\title{
Philosophiques
}

\section{Livres reçus (printemps 2008)}

Volume 35, numéro 1, printemps 2008

Les valeurs de l'ironie (1) et le scepticisme à l'âge classique (2)

URI : https://id.erudit.org/iderudit/018251ar

DOI : https://doi.org/10.7202/018251ar

Aller au sommaire du numéro

Éditeur(s)

Société de philosophie du Québec

ISSN

0316-2923 (imprimé)

1492-1391 (numérique)

Découvrir la revue

Citer ce document

(2008). Livres reçus (printemps 2008). Philosophiques, 35(1), 291-291.

https://doi.org/10.7202/018251ar d'utilisation que vous pouvez consulter en ligne.

https://apropos.erudit.org/fr/usagers/politique-dutilisation/ 


\section{Livres reçus (printemps 2008)}

Devaux, Philippe, La cosmologie de Whitehead. Tome I, l'épistémologie whiteheadienne, Bruxelles, Les éditions Chromatika, 2007, 340 p.

Esfeld, Michael, La philosophie de l'esprit. De la relation entre l'esprit et la nature, Paris,

Armand Colin, 2005, 201 p.

Fisette, Denis et Fréchette, Guillaume (dir.), À l'école de Brentano. De Würzburg à Vienne, Paris, Vrin (coll.: "Bibliothèque des Textes Philosophiques »), 2007, 448 p.

Leroux, Georges, Éthique, culture religieuse, dialogue. Arguments pour un programme, Montréal, Fides, 2007, 118 p.

Nadeau, Christian, Justice et démocratie : une introduction à la philosophie politique, Montréal, Presses de l'Université de Montréal, 2007, 186 p.

McDowell, John, L'esprit et le monde, trad. par C. Alsaleh, Paris, Vrin (coll. : « Analyse et philosophie "), 2007, 240 p.

Saint-Germain, Christian, L'œil sans la paupière. Écrire l'émotion pornographique, Montréal, Presses de l'Université du Québec (coll. : Des mots et des idées), 2003, 90 p.

Woodruff Smith, David, Husserl, Londres et New York, Routledge (coll.: "The Routledge Philosophers »), 2006, 248 p. 